\title{
UGT1A1 Gene Polymorphisms in North Indian Neonates Presenting with Unconjugated Hyperbilirubinemia
}

\author{
SUNIL K. AGRAWAL, PRAVEEN KUMAR, RITU RATHI, NEERAJ SHARMA, REENA DAS, RAJENDRA PRASAD, \\ AND ANIL NARANG
}

\author{
Department of Pediatrics [S.K.A., P.K., A.N.], Department of Biochemistry [R.R., N.S., R.P.], Department of Hematology [R.D.], \\ Postgraduate Institute of Medical Education and Research, Chandigarh 160012, India
}

\begin{abstract}
Genetic factors are implicated in pathogenesis of neonatal hyperbilirubinemia. In this nested case-control study, we determined 1) frequency of thymine-adenine (TA) ${ }_{n}$ promoter polymorphism and Gly71Arg mutation in uridine diphosphoglucuronateglucuronosyltransferase 1A1 (UGT1A1) gene in neonates $\geq 35$-wk gestation presenting with bilirubin levels $\geq 18 \mathrm{mg} / \mathrm{dL}$ and controls, 2) interaction among $(\mathrm{TA})_{n}$ promoter polymorphism, glucose-6phosphate dehydrogenase $(G 6 P D)$ gene mutations, and peak bilirubin. The number of TA repeats was assessed by PCR-single-strand conformation polymorphism (SSCP) analysis and Gly71Arg mutation by PCR-RFLP. Fifty samples of both mutations were verified with DNA sequencing. One hundred twenty-seven neonates were enrolled (77 hyperbilirubinemics, 50 controls). The incidence of (TA) ${ }_{n}$ polymorphism was higher in babies with hyperbilirubinemia [89.6\% vs. 50\%, OR 8.63 (95\% CI, 3.2-24.1)]. Gly71Arg mutation was not found either in hyperbilirubinemics or controls. A novel polymorphism (Ala72Pro) at codon position 72 of exon 1 was detected in all 50 samples (21 hyperbilirubinemics, 29 controls), which were sequenced. Presence of variant (TA) $n$ promoter (adjusted OR, 10.6; 95\% CI, 3.3-34.2), G6PD deficiency (adjusted OR, 20.6; 95\% CI, 3.6-117.3), and history of jaundice in sibling requiring phototherapy (adjusted OR, 12.6; 95\% CI, 1.1-141.6) were independent risk factors for bilirubin levels $\geq 18 \mathrm{mg} / \mathrm{dL}$. (Pediatr Res 65: 675-680, 2009)
\end{abstract}

$\mathrm{T}_{\mathrm{i}}^{\mathrm{k}}$ The incidence and severity of neonatal hyperbilirubinemia is significantly higher in Asians, more so in North Indians, than in Caucasians $(1,2)$. Despite all standard investigations, no cause is identified in $48-58 \%$ of these cases $(2,3)$. Genetic factors have been implicated in such situations; however, their contribution in Indian population has not been reported. Genetic variants involving red blood cell enzyme glucose-6phosphate dehydrogenase (EC 1.1.1.49; G6PD) and bilirubin conjugating enzyme uridine diphosphoglucuronate-glucuronosyltransferase 1A1 (EC 2.4.1.17; UGT1A1) have been commonly associated with neonatal hyperbilirubinemia $(4,5)$. The usual polymorphism described in Caucasians is additional thymine-adenine (TA) insertions in the normal sequence A(TA) ${ }_{6}$ TAA of the TATAA box promoter of the UGT1A1 gene (6). However, in East Asians, missence mutations in the coding area of the UGTIAl gene, especially $\mathrm{G} \rightarrow \mathrm{A}$ transition

Received October 6, 2008; accepted January 17, 2009.

Correspondence: Praveen Kumar, M.D., D.M., Department of Pediatrics, Post Graduate Institute of Medical Education and Research, Chandigarh 160012, India; e-mail: drpkumarpgi@gmail.com

Supported, in part, by the Indian Council of Medical Research, India. at nucleotide position 211 of exon 1 (Gly71Arg) are the most common (7). The types, prevalence, and importance of various mutations of UGT1Al gene vary across different regions of world.

Hence, this study was conducted with the primary objective of determining the frequency of (TA $)_{n}$ promoter polymorphism and Gly71Arg mutation in the UGT1Al gene in North Indian neonates $\geq 35$-wk gestation presenting with serum total bilirubin $(\mathrm{STB}) \geq 18 \mathrm{mg} / \mathrm{dL}$. The secondary objective was to study the interaction among the presence of UGT1Al gene polymorphisms, G6PD gene mutations, and peak STB levels.

\section{PATIENTS AND METHODS}

This was a hospital-based nested case-control study, conducted over a period of $1 \mathrm{y}$ from July 2006 to June 2007 in a tertiary care referral neonatal unit in North India. The Ethics Committee of Postgraduate Institute of Medical Education and Research approved the study and a written informed consent was taken from one of the parents before inclusion into the study.

Study population. All inborn neonates $\geq 35$-wk gestation born during the study period were assessed for eligibility. Clinical assessment of jaundice was done twice daily by a neonatology fellow and STB was measured as and when required. All inborn babies were monitored until day 7 of life for the peak STB. Those who developed STB of $\geq 18 \mathrm{mg} / \mathrm{dL}$ were enrolled as cases. Babies were enrolled as controls if there was no clinical jaundice or the peak STB was $<15 \mathrm{mg} / \mathrm{dL}$ and they had not received phototherapy or exchange transfusion previously. Neonates $\geq 35$ wk of gestation referred from outside (outborn neonates) in the first $2 \mathrm{wk}$ of life were also assessed for eligibility and enrolled as cases if STB was $\geq 18 \mathrm{mg} / \mathrm{dL}$. Those with evidence of obvious hemolysis (elevated reticulocyte count, fall in $\mathrm{Hb}$ and a peripheral smear showing spherocytes, nucleated RBCs, anisopoikilocytosis), positive direct Coombs' test, prior blood transfusion or exchange transfusion or conjugated bilirubin $>20 \%$ of the STB were excluded. Acute bilirubin encephalopathy was diagnosed and classified into three phases as per neurologic features described by Volpe (8).

Laboratory investigations. The following investigations were done on all enrolled neonates including controls to diagnose the known causes of hyperbilirubinemia: blood grouping ( $\mathrm{ABO}$ and Rh typing) of baby and mother, direct Coombs' test (baby), complete blood cell counts, peripheral blood smear, reticulocyte count and G6PD enzyme activity, both by qualitative (methemoglobin reduction test) and quantitative assay. Quantitative G6PD enzyme activity was measured as per the method described by Kornberg and Horecker (9) with RANDOX diagnostic kit (RANDOX Laboratories, United Kingdom). In addition, $2 \mathrm{~mL}$ of venous blood was drawn in a vial containing $500 \mu \mathrm{L}$ of ACD (as an anticoagulant) and DNA was isolated by the method of Daly et al. (10). All the DNA samples were analyzed for the number of TA repeats and Gly71Arg mutation in the promoter region and exon 1 of UGT1A1 gene, respectively, and also for G6PD Mediterranean and G6PD Orissa mutations.

Abbreviations: G6PD, glucose-6-phosphate dehydrogenase; SSCP, singlestrand conformation polymorphism; STB, serum total bilirubin; TA, thymineadenine; UGT1A1, uridine diphosphoglucuronate-glucuronosyltransferase 1A1 
Single-strand conformation polymorphism (SSCP) analysis of promoter area of the UGT1A1 gene for detection of number of TA repeats. The number of TA repeats was determined by amplification of the promoter area of the UGT1A1 gene by PCR followed by SSCP analysis. The promoter area of UGT1A1 gene was amplified from genomic DNA by using primers Bili $\times$ forward: 5'-ATTAACTTGGTGTCGATTGG-3' and Bili z reverse: 5'-AGCCATGGCGGCCTTTGCTC-3' which amplified a 90-bp (wild type) or 92-bp (variant) DNA fragment as described by Kaplan et al. (11). Amplified PCR products were subjected to mutational analysis using SSCP as described by Kumar et al. (12). To assign a genotype to a SSCP pattern, representative samples from both cases and controls (a total of 50) showing each of the patterns were sequenced to know the number of TA repeats in a DNA sequencer ABI Prism (Model 3100, Perkin Elmer, USA). Genotypes were assigned as follows: (TA) $)_{6 / 6}$ (homozygous with 6 TA repeats), (TA $)_{6 / 7}$ (heterozygous with one allele with 6 TA repeats and one allele with 7 TA repeats), (TA) $7 / 7$ (homozygous with 7 TA repeats), (TA) $6 / 8$ (heterozygous with one allele with 6 TA repeats and one allele with 8 TA repeats), (TA) (heterozygous with one allele with 7 TA repeats and one allele with 8 TA repeats), and (TA) $)_{8 / 8}$ (homozygous with 8 TA repeats).

Detection of Gly71Arg mutation of the UGT1A1 gene. For detection of Gly71Arg mutation, the exon 1 of the UGT1A1 gene was first amplified from genomic DNA by using primers U1F1 forward: 5'-AGATACTGTTGATCCCAGTG-3' and U211R reverse: 5'-CTTCAAGGTGTAAAATGGTC-3', which was followed by restriction digestion with AvaII (NEB, USA) (13). For confirmation, 50 samples from both cases and controls were randomly selected and subjected to automated DNA sequencing.

Detection of G6PD gene mutations. All samples irrespective of their G6PD screening status underwent mutational analysis for G6PD Mediterranean $(536 \mathrm{C} \rightarrow \mathrm{T})$ and $\mathrm{G} 6 \mathrm{PD}$ Orissa $(131 \mathrm{C} \rightarrow \mathrm{G})$ mutation by the PCR-RFLP method. For G6PD Mediterranean mutation, the primers used were G1 forward: 5'-ACTCCCCGAAGAGGGGTTCAAGG-3' and G2 reverse: 5'CCAGCCTCCCAGGAGAGAGGAAG- $3^{\prime}$ and the restriction enzyme used was MboII. For G6PD Orissa mutation, the primers used are G3 forward: 5'-CAGCCACTTCTAACCACACACCT-3' and G4 reverse: 5'-CCGAAGTTGGCCATGCTGGG-3' and the restriction enzyme used was HaeIII.

Classification of G6PD enzyme activity and labeling of G6PD deficiency. For calculation of normative values, babies whose G6PD qualitative assay (methemoglobin reduction test) was normal and who were not having either G6PD Mediterranean or Orissa mutation were considered as G6PD normal. The mean (SD) enzyme activity for the G6PD normal males $(n=60)$ was $6.45(2.1) \mathrm{U} / \mathrm{g} \mathrm{Hb}$ while that for the G6PD normal females $(n=39)$ was 6.05 (1.6) $\mathrm{U} / \mathrm{g} \mathrm{Hb}$. Hence, a G6PD activity of $<2.2 \mathrm{U} / \mathrm{g} \mathrm{Hb}$ in males and $<2.8 \mathrm{U} / \mathrm{g}$ $\mathrm{Hb}$ in females was taken as indicative of deficiency.

For analysis, we defined G6PD deficient (G6PD-D) as the one who was either having the mutation or having the enzyme activity $<2 \mathrm{SD}$ of the normal mean.

Monitoring and treatment protocol. The STB was measured 8-12 $\mathrm{h}$ while conjugated bilirubin fraction was done once initially and repeated subsequently if indicated. STB was estimated by direct spectrophotometry using twin-beam bilirubinometer (BIL-100, Cosmo Medical, Korea; coefficient of variation, $3 \%$ ). Conjugated bilirubin fraction was estimated by Jendrassik and Grof method (14). The babies were followed for peak STB, duration of phototherapy, need for exchange transfusion, and resolution of jaundice. The highest value of STB was taken as the peak STB. The decision to start and stop phototherapy or do an exchange transfusion was as per unit protocol, which is a modification of the American Academy of Pediatrics (AAP), revised guidelines published in the year 2004 (15). We follow the medium risk line for neonates $\geq 38 \mathrm{wk}$ of gestation with no risk factors and the high-risk line for others. The modification has been done because certain risk factors listed in the AAP charts-G6PD deficiency, low serum albumin, Asian race-which make a baby jump one-risk line are present very commonly in our population and cannot be immediately excluded in a baby reporting with severe hyperbilirubinemia.

Outcome measures. The primary outcome was frequency of the (TA) promoter polymorphism and Gly71Arg mutation of the UGT1A1 gene and the secondary outcomes were peak STB level and duration of phototherapy.

Sample size. The mean allele frequency of (TA $)_{7}$ TAA promoter polymorphism has been reported to be 0.38 in healthy adult population of Indian origin (16-18). Assuming an effect size of 2, with a two-sided alpha of 0.05 and $90 \%$ power, 36 babies per group were required for the study. Similarly from the available literature, the mean allele frequency of Gly71Arg mutation in hyperbilirubinemic neonates was calculated as 0.35 as against 0.10 in the nonhyperbilirubinemic neonates $(4,19-21)$. With a two-tailed $\alpha$ of 0.05 and $80 \%$ power, 43 babies per group were required to be studied. To account for attrition and technical problems, at least 50 babies each in the study and control groups were planned to be studied.

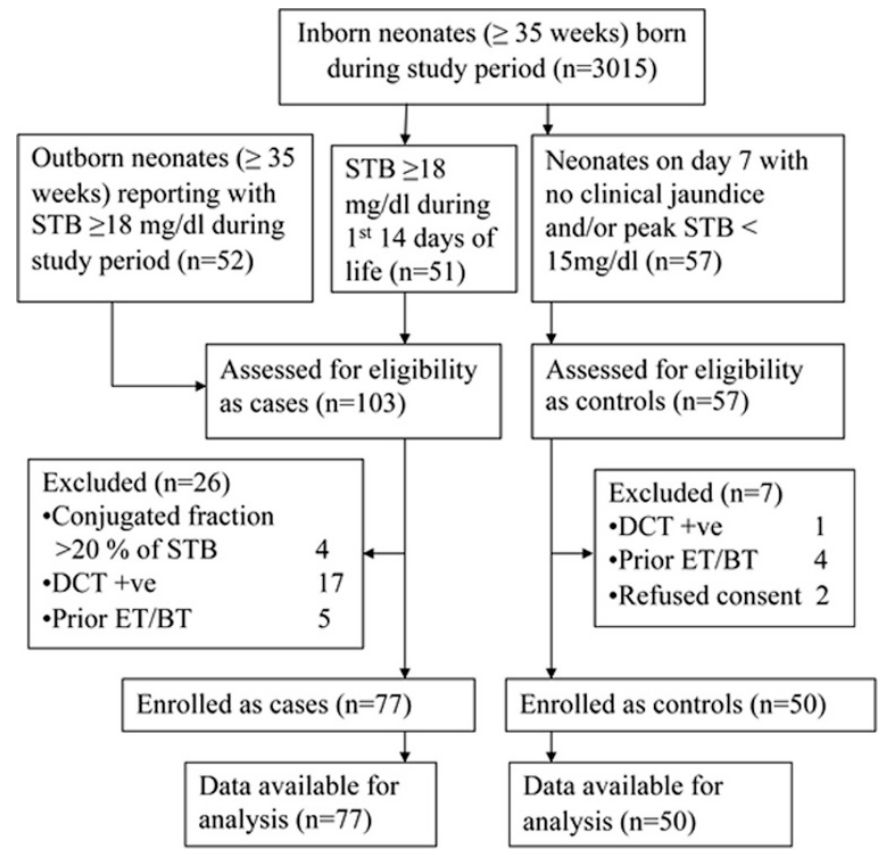

Figure 1. Flow of participants in the study. DCT, direct Coombs' test; ET, exchange transfusion; BT, blood transfusion.

Statistical analysis. The baseline demographic data between the study group and the control were compared using $\chi^{2}$ test for categorical variables and student's $t$ test for continuous variables. Genotype and allele frequencies of (TA $)_{n}$ promoter polymorphism and Gly71Arg mutation were compared using $\chi^{2}$ test. The various jaundice parameters were compared across different genotype groups using one-way ANOVA, Kruskal-Walis, and $\chi^{2}$ for trend as applicable. The association of risk factors with STB $\geq 18 \mathrm{mg} / \mathrm{dL}$ was assessed by logistic regression analysis. The following parameters were entered in the model: gestational age, sex, oxytocin use during delivery, history of jaundice in sibling requiring phototherapy, presence of $\mathrm{ABO}$ setting (mother blood group $\mathrm{O}$ and baby blood group A or B), G6PD status, and variant promoter UGTIA1.

\section{RESULTS}

Figure 1 depicts the flow of participants in the study. Seventy-seven newborns $\geq 35$-wk gestation (33 inborn, 44 outborn) with STB $\geq 18 \mathrm{mg} / \mathrm{dL}$ were enrolled as cases and 50 newborns with peak STB $<15 \mathrm{mg} / \mathrm{dL}$ were enrolled as controls. The baseline characteristics of the two groups are shown in Table 1. None of the babies in either group had cephalhematoma or significant wt loss ( $\geq 10 \%$ of birth weight). Of the 77 babies in the hyperbilirubinemic group, 54 underwent exchange transfusion (12 inborn, 42 outborn) and 13 had features of acute bilirubin encephalopathy (ABE). The peak STB was in the range of $20.0-24.9 \mathrm{mg} / \mathrm{dL}$ in 34 babies and $\geq 25 \mathrm{mg} / \mathrm{dL}$ in 24 . Of the 13 babies with ABE, the peak STB was between 20.0 and $24.9 \mathrm{mg} / \mathrm{dL}$ in 2 and $\geq 25 \mathrm{mg} / \mathrm{dL}$ in 11 .

Frequency of $(T A)_{n}$ polymorphism in the promoter area of UGT1A1 gene. As seen in Figure 2, distinct SSCP patterns could be obtained. All of these patterns were verified with automated DNA sequencing (Fig. 3). Table 2 shows the frequencies of different genotypes in the two groups. A higher proportion of babies in the hyperbilirubinemic group had variation of the (TA) ${ }_{n}$ promoter compared with control group (89.6\% vs. $50 \%, p=0.001)$. The frequency of $(\mathrm{TA})_{7}$ and 
Table 1. Comparison of baseline variables

\begin{tabular}{|c|c|c|c|}
\hline Baseline characteristics & Study group $(n=77)$ & Control group $(n=50)$ & $p$ \\
\hline Gestational age in wk, mean (SD) & $37.7(1.5)$ & $37.9(1.5)$ & 0.29 \\
\hline Birth weight in g, mean (SD) & $2590(514)$ & $2633(503)$ & 0.64 \\
\hline Males $(\%)$ & $43(56)$ & $35(70)$ & 0.11 \\
\hline Small for gestational age (\%) & $4(5)$ & $3(6)$ & 1.00 \\
\hline Cesarean delivery $(\%)$ & $16(21)$ & $24(48)$ & 0.012 \\
\hline Instrumental delivery $(\%)$ & $3(4)$ & $1(2)$ & 1.0 \\
\hline Oxytocin use during delivery $(\%)$ & $17(22)$ & $5(10)$ & 0.079 \\
\hline $\mathrm{H} / \mathrm{o}$ jaundice in sibling requiring phototherapy $(\%)$ & $11(14)$ & $1(2)$ & 0.027 \\
\hline Born to primipara mother $(\%)$ & $39(51)$ & $22(44)$ & 0.46 \\
\hline Peak STB in mg/dL, mean (SD) & $23.1(3.7)$ & $8.2(3.5)$ & $<0.001$ \\
\hline ABO setting* $(\%)$ & $11(14)$ & $8(16)$ & 0.79 \\
\hline Outborn and referred $(\%)$ & $44(57)$ & $0(0)$ & $<0.001$ \\
\hline Exclusive breast feeding (\%) & $51(66)$ & $32(64)$ & 0.79 \\
\hline
\end{tabular}

Figures in parenthesis are percentages or SDs.

* Mother blood group O and baby blood group A or B.

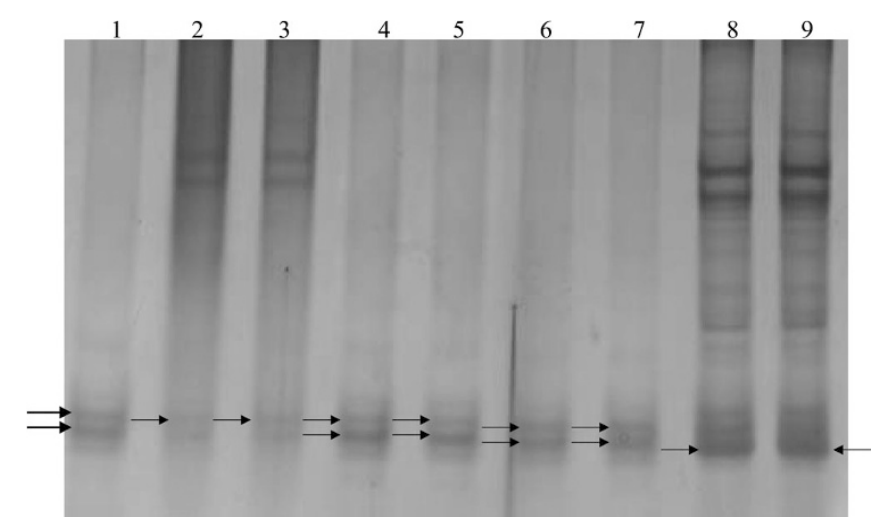

Figure 2. A SSCP gel showing mobility shifts. Lane 8 and 9 correspond to wild genotype $(\mathrm{TA})_{6} /(\mathrm{TA})_{6}$, Lanes 1 and $4-7$ correspond to heterozygous genotype $(\mathrm{TA})_{6} /(\mathrm{TA})_{7}$ and Lanes $2-3$ correspond to homozygous genotype $(\mathrm{TA})_{7} /(\mathrm{TA})_{7}$. Arrows indicate mobility shifts. Genotypes were assigned after nucleotide sequencing.

A

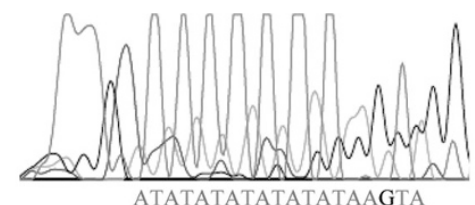

B

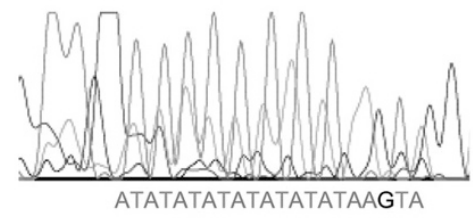

C

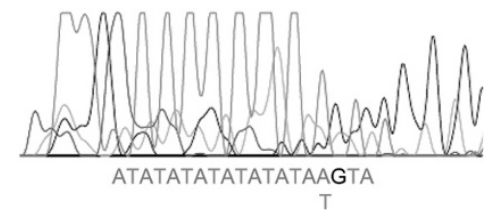

Figure 3. Segments of the DNA sequence of the promoter region of UGT1A1 gene to characterize polymorphic TA repeats. Genotype of the baby $(A)$ is $(\mathrm{TA})_{6} /(\mathrm{TA})_{6}$, of $(B)$ is $(\mathrm{TA})_{7} /(\mathrm{TA})_{7}$ and of $(C)$ is $(\mathrm{TA})_{6} /(\mathrm{TA})_{7}$.

$(\mathrm{TA})_{8}$ alleles was also significantly higher in the hyperbilirubinemic neonates (Table 3 ). (TA) 5 allele was not found either in controls or in hyperbilirubinemic babies.

Frequency of Gly71Arg mutation in the exon 1 of UGT1A1 gene. We did not find any substitution of glycine to arginine at amino acid position 71 of exon 1 of UGTIAl gene. All the samples were bearing the nucleotide $\mathrm{G}$ at position 211 .

Detection of a novel polymorphism (Ala72Pro) at nucleotide position $214(G \rightarrow C)$ of the exon 1 of UGT1A1 gene. The normal codon at the position 72 of the exon 1 of UGTIAI gene is GCA, which codes for the amino acid alanine. In all the 50 samples (21 cases and 29 controls), which were sequenced, we found CCA at the codon position 72 (Fig. 4). This caused the change of codon from GCA to CCA, which codes for the amino acid proline.

Effect of TA repetition number on jaundice parameters in the study group. In the hyperbilirubinemic group, parameters related to jaundice among babies carrying different genotypes are shown in Table 4 . We did not find any significant difference in the peak STB or need for exchange transfusion between different genotype groups. As the number of TA repeats increased, the duration of phototherapy was longer and the day on which peak STB was reached was earlier but these differences did not achieve statistical significance.

Characterization of G6PD gene mutations. Of the 77 hyperbilirubinemics, 19 babies had G6PD Mediterranean mutation (12 were hemizygous males, 6 were heterozygous females, and 1 was homozygous female) and 2 had Orissa mutation ( 1 was hemizygous male and the other heterozygous female). In controls, none had any G6PD mutation. The incidence of mutant $G 6 P D$ gene was $27.3 \%$ in hyperbilirubinemics and $0 \%$ in controls $(p<0.001)$. All 21 babies with G6PD mutations had quantitative G6PD activity $<2$ SD of the normal. In addition three babies, who did not show the presence of G6PD Mediterranean or Orissa mutation, had quantitative G6PD activity $<2 \mathrm{SD}$ of the normal and they were also labeled as G6PD deficient (G6PD-D) for analysis.

Interaction of G6PD deficiency and TA repetition number on jaundice parameters in the study group. In the hyperbilirubinemic group, the effects of TA repeat number and G6PD status on parameters related to neonatal jaundice is summarized in Table 5. Of the 74 hyperbilirubinemic, 50 were G6PD-N (normal) and 24 were G6PD-D (deficient). There was no significant change in various parameters related to neonatal jaundice in G6PD-D group as their TA number increased (Table 5). The data of babies having proven G6PD 
Table 2. Genotype frequencies of $(T A)_{n}$ promoter polymorphism

\begin{tabular}{|c|c|c|c|c|}
\hline Genotype & Study group $(n=77)$ & Control group $(n=50)$ & Odds ratio $(95 \% \mathrm{CI})$ & $p$ \\
\hline \multicolumn{5}{|l|}{ Wild type } \\
\hline$(\mathrm{TA})_{6} /(\mathrm{TA})_{6}$ & $8(10.4)$ & $25(50)$ & $0.12(0.04-0.31)$ & $<0.001$ \\
\hline \multicolumn{5}{|l|}{ Variant promoter } \\
\hline Any variation & $69(89.6)$ & $25(50)$ & $8.63(3.2-24.1)$ & $<0.001$ \\
\hline$(\mathrm{TA})_{6} /(\mathrm{TA})_{7}$ & $49(63.6)$ & $21(42)$ & $2.42(1.1-5.36)$ & 0.02 \\
\hline$(\mathrm{TA})_{7} /(\mathrm{TA})_{7}$ & $12(15.6)$ & $4(8)$ & $2.12(0.64-6.9)$ & 0.21 \\
\hline$(\mathrm{TA})_{6} /(\mathrm{TA})_{8}$ & $5(6.5)$ & 0 & - & 0.06 \\
\hline$(\mathrm{TA})_{7} /(\mathrm{TA})_{8}$ & $2(2.6)$ & 0 & - & 0.5 \\
\hline$(\mathrm{TA})_{8} /(\mathrm{TA})_{8}$ & $1(1.3)$ & 0 & - & 1.0 \\
\hline
\end{tabular}

Figures in parenthesis are percentage or $95 \%$ confidence intervals as applicable.

$\chi^{2}$ for trend $(p<0.001)$.

Table 3. Allele frequencies of $(T A)_{n}$ promoter polymorphism

\begin{tabular}{cccc}
\hline Allele type & Study group $(n=77)$ & Control group $(n=50)$ & Odds ratio $(95 \% \mathrm{CI})$ \\
\hline$(\mathrm{TA})_{6}$ & 0.455 & 0.71 & $0.34(0.19-0.6)$ \\
$(\mathrm{TA})_{7}$ & 0.487 & 0.29 & $2.32(1.32-4.12)$ \\
$(\mathrm{TA})_{8}$ & 0.058 & 0 & - \\
\hline
\end{tabular}

$\chi^{2}$ for trend $(p<0.001)$.

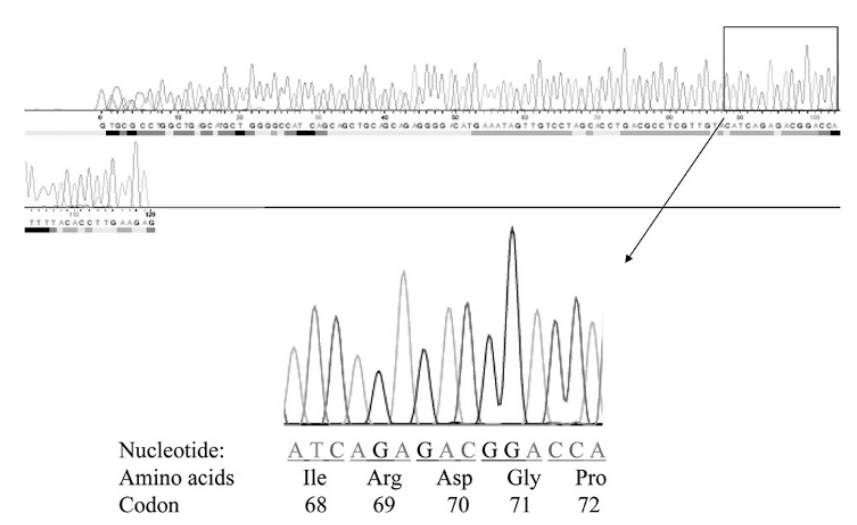

Figure 4. A segment of the DNA sequence of exon 1 of UGT1A1 gene. Inset shows glycine at codon 71 and at codon 72 , wild-type alanine (GCA) has been substituted by proline (CCA).

Mediterranean or G6PD Orissa mutation was also analyzed separately and the results were similar (data not shown).

Maternal and neonatal factors associated with bilirubin levels $\geq 18 \mathrm{mg} / \mathrm{dL}$. The risk of developing severe unconjugated hyperbilirubinemia for each of the factors, independent of the other's effect, was estimated by logistic regression analysis. The presence of variant (TA) ${ }_{n}$ promoter (adjusted OR, 10.6; 95\% CI, 3.3-34.2), G6PD deficiency (adjusted OR, 20.6; 95\% CI, 3.6-117.3), and history of jaundice in sibling requiring phototherapy (adjusted OR, 12.6; 95\% CI, 1.1141.6) were independent predictors of bilirubin levels $\geq 18$ $\mathrm{mg} / \mathrm{dL}$. The adjusted $R^{2}$ value of the model was 0.31 .

\section{DISCUSSION}

The causes of neonatal hyperbilirubinemia are multifactorial and comprise increased bilirubin production on one hand, and diminished conjugation on the other. In recent years, many of these etiologies have been found to have a genetic origin in various parts of the world. In North Indian neonates, we found a higher frequency of (TA) ${ }_{n}$ promoter polymorphism in hyperbilirubinemic subjects compared with controls.
This observation is in accordance with the findings of Laforgia et al. who found significantly higher frequency for the variant $(\mathrm{TA})_{7} /(\mathrm{TA})_{7}$ genotype in Italian neonates with STB concentrations $>13 \mathrm{mg} / \mathrm{dL}$ compared with controls whose STB values did not exceed that concentration $(26.8 \%$ vs. $12.2 \%$, $p<0.05)$ (22). However, in case-control studies done on Turkish neonates, no significant difference in the frequency of variant promoter between jaundiced babies and controls were found $(23,24)$. This could be because of differences in enrollment criteria or geographical differences in the incidence of $(\mathrm{TA})_{n}$ promoter polymorphism.

The allele frequency of variant $(\mathrm{TA})_{7}$ in our study population and controls was $48.7 \%$ and $29 \%$, respectively. The allele frequency of $(\mathrm{TA})_{7}$ reported in healthy adult population of Indian origin was $35 \%$ in a study done on migrated Indians in Singapore (16), 38\% in a report from Eastern India (17) and $41 \%$ in a study from Northern India (18). The variant (TA) 8 has not been reported earlier in Indian population. We found $(\mathrm{TA})_{8}$ allele only in the hyperbilirubinemic subjects, the allele frequency being $5.8 \%$. This allele was first described by Beutler et al. (25) in $6.9 \%$ of healthy individuals of North and Central America with varying degrees of African ancestry. In their study, using a reporter gene, they showed that there is an inverse relationship between number of TA repeats and the activity of promoter through the range of 5 to 8 TA repeats. $(\mathrm{TA})_{8}$ allele is very rare in Caucasians; despite many published studies, only a few cases have been described $(26,27)$.

Bancroft et al. (28) who measured transcutaneous bilirubin index in first $2 \mathrm{~d}$ of life and Roy-Chowdhury et al. (29)who measured STB values at $96 \mathrm{~h}$ of life found higher values of STB in neonates homozygous for the variant $(\mathrm{TA})_{7}$ promoter compared with homozygous normal (TA) ${ }_{6}$ controls. The onset of jaundice and peak STB values in the various genotype groups in our study was not different statistically. However, there was a trend of earlier attainment of peak STB and increasing duration of phototherapy as TA repeat number increased. This may be because the majority of babies in our 
Table 4. Effect of TA repeat number on jaundice parameters in study group $(n=77)$

\begin{tabular}{|c|c|c|c|c|}
\hline Jaundice parameters & Wild type $(n=8)$ & Heterozygous $(n=49)$ & Homozygous/compound heterozygous $(n=20)$ & $p$ \\
\hline Peak STB in $\mathrm{mg} / \mathrm{dL}$, mean (SD)* & $24.7(4)$ & $23.3(4)$ & $22.2(3)$ & 0.25 \\
\hline Day on which jaundice first noticed, median (IQR) $\dagger$ & $4(3,5)$ & $3(3,4)$ & $3(3,4)$ & 0.19 \\
\hline PT duration in $\mathrm{h}$, median $(\mathrm{IQR}) \dagger$ & $61(30,87)$ & $72(52,84)$ & $60(48,81)$ & 0.52 \\
\hline Need for ET $(\%) \neq$ & $7(88)$ & $35(71)$ & $12(60)$ & 0.14 \\
\hline $\mathrm{ABE}(\%) \ddagger$ & $2(25)$ & $8(16)$ & $3(15)$ & 0.59 \\
\hline Day of peak STB, median $(\mathrm{IQR}) \dagger$ & $6(4,10)$ & $5(4,6)$ & $4(4,5)$ & 0.11 \\
\hline
\end{tabular}

Wild type, $(\mathrm{TA})_{6} /(\mathrm{TA})_{6} ;$ Heterozygous, $(\mathrm{TA})_{6} /(\mathrm{TA})_{7} ;$ Homozygous/compound heterozygous, $(\mathrm{TA})_{7} /(\mathrm{TA})_{7}$ or $(\mathrm{TA})_{6} /(\mathrm{TA})_{8}$ or $(\mathrm{TA})_{7} /(\mathrm{TA})_{8}$ or $(\mathrm{TA})_{8} /(\mathrm{TA})_{8} ;$ ET, exchange transfusion; ABE, acute bilirubin encephalopathy.

* One-way ANOVA.

$\dagger$ Kruskal-Wallis.

$\ddagger \chi^{2}$ for trend.

Table 5. Jaundice parameters in the study group according to TA repeat number and G6PD status $(n=74)$

\begin{tabular}{|c|c|c|c|c|c|c|c|}
\hline \multirow[b]{2}{*}{ Jaundice parameters } & \multicolumn{2}{|c|}{ Wild type } & \multicolumn{2}{|c|}{ Heterozygous } & \multicolumn{2}{|c|}{$\begin{array}{c}\text { Homozygous/compound } \\
\text { heterozygous }\end{array}$} & \multirow[b]{2}{*}{$p$} \\
\hline & $\begin{array}{c}\text { G6PD-N } \\
(n=4)\end{array}$ & $\begin{array}{l}\text { G6PD-D } \\
(n=4)\end{array}$ & $\begin{array}{l}\text { G6PD-N } \\
(n=31)\end{array}$ & $\begin{array}{l}\text { G6PD-D } \\
(n=17)\end{array}$ & $\begin{array}{l}\text { G6PD-N } \\
(n=15)\end{array}$ & $\begin{array}{l}\text { G6PD-D } \\
(n=3)\end{array}$ & \\
\hline Peak STB in $\mathrm{mg} / \mathrm{dL}$, mean $(\mathrm{SD})^{*}$ & $22.6(3)$ & $26.7(3)$ & $23(4)$ & $23.9(3)$ & $22.3(3)$ & $21.6(3)$ & 0.13 \\
\hline Day on which jaundice first noticed median (IQR) $\dagger$ & $3(3,5)$ & $4(4,9)$ & $4(3,4)$ & $3(3,4)$ & $3(3,4)$ & $4(3,5)$ & 0.057 \\
\hline PT duration in $\mathrm{h}$, median $(\mathrm{IQR}) \dagger$ & $49(21,84)$ & $72(36,87)$ & $72(48,72)$ & $84(59,96)$ & $60(48,72)$ & $72(60,120)$ & 0.65 \\
\hline Need for ET $(\%) \ddagger$ & $3(75)$ & $4(100)$ & $20(65)$ & $14(82)$ & $9(60)$ & $2(67)$ & 0.24 \\
\hline $\operatorname{ABE}(\%) \ddagger$ & 0 & $2(50)$ & $3(10)$ & $5(28)$ & $2(13.3)$ & $1(20)$ & 0.59 \\
\hline Day of peak STB, median (IQR) $\dagger$ & $6(4,10)$ & $6(4,10)$ & $5(4,5)$ & $5(4,6)$ & $4(3,5)$ & $5(4,6)$ & 0.52 \\
\hline
\end{tabular}

Wild type, $(\mathrm{TA})_{6} /(\mathrm{TA})_{6}$; Heterozygous, $(\mathrm{TA})_{6} /(\mathrm{TA})_{7} ;$ Homozygous/compound heterozygous, $(\mathrm{TA})_{7} /(\mathrm{TA})_{7}$ or $(\mathrm{TA})_{6} /(\mathrm{TA})_{8}$ or $(\mathrm{TA})_{7} /(\mathrm{TA})_{8}$ or $(\mathrm{TA})_{8} /(\mathrm{TA})_{8}$; G6PD-D, G6PD deficient; G6PD-N, G6PD normal; ET, exchange transfusion; ABE, acute bilirubin encephalopathy.

* One-way ANOVA.

$\dagger$ Kruskal-Wallis.

$\ddagger \chi^{2}$ for trend.

study received phototherapy and/or exchange transfusion, which may have altered the peak STB. The duration of phototherapy can be a surrogate marker for severity of jaundice but again that would have been modified with exchange transfusions, as $70 \%$ of the jaundiced babies underwent exchange transfusion.

There was no significant interaction between G6PD deficiency and TA promoter polymorphism in our study. Two Italian case-control studies also reported no significant interaction between G6PD deficiency and (TA) $n$ promoter polymorphism among those who developed hyperbilirubinemia (30,31). However, Kaplan and Hammerman (4) described that in G6PD deficient Israeli neonates, superimposition of the variant UGT1A1 promoter resulted in a significant increase in the incidence of hyperbilirubinemia in an allele dosedependent response. However, their study design was different in that, they took G6PD deficient and G6PD normal neonates with no other risk factors for neonatal hyperbilirubinemia (except G6PD deficiency) and reported the percentage developing hyperbilirubinemia with respect to their UGT1A1 variant genotype status. When Kaplan et al. (32) analyzed their data in the manner we have done, they did not find any significant interaction between G6PD deficiency and TA promoter polymorphism. Therefore, the differences in the findings among various studies may be related to study design or the interactions may actually be population specific.

In this study, Gly71Arg mutation in the exon 1 of UGTIAI gene was not found either in heterozygous or homozygous state in all hyperbilirubinemic and control subjects. This mutation has been frequently reported in hyperbilirubinemic patients of Gilbert syndrome from East Asian populations including Japanese, Korean, Chinese, and Taiwanese. It is noteworthy that Gly71Arg mutation has not been reported in Caucasian Gilbert's syndrome patients.

Incidentally, in all 100 chromosomes (50 patients) where sequencing was done, we found CCA at the codon position 72 of the exon 1 of UGTIAl gene instead of the codon GCA described. This changed the amino acid at position 72 from alanine to proline (Ala72Pro). Ritter et al. (33) have described two cDNA clones viz HUG-Br1 and HUG-Br2, which each encodes a UGT1A1 enzyme. The codon sequence at 72 position was GCA for HUG-Br1 cDNA and was AAA for HUG-Br2, both the types described did not contain the codon CCA reported in this study. This single nucleotide polymorphism (SNP) has not been reported earlier (GenBank accession number F J222555). The effect of Ala72Pro on mRNA and protein expression needs to be explored. It has been seen that mutations found in exon 1 might reduce the affinity of the ligand, bilirubin, for the catalytic site in the amino-terminal half of the molecule, which is encoded by exon 1 of the UGT1Al gene. However, because it was found both in control and jaundiced neonates, one can speculate that it may not affect the glucuronidation activity significantly. We also checked the effect of our polymorphism at the website SNP structure, function, disease, which assigns molecular functional effects of nonsynonymous SNPs based on structure and sequence analysis (34). The support vector machine (SVM) score for our novel polymorphism was 2.4 and it was classi- 
fied as a nondeleterious variant. UGT1A1 polymorphisms are known to predispose individuals to altered metabolism and enhanced toxicity of several drugs such as paracetamol, propofol, irinotecan, indinavir, which are substrates for glucuronidation by UGT1A1. The importance of this new polymorphism vis-à-vis drug metabolism or other metabolic pathway needs to be explored.

Although we found (TA) $n$ promoter polymorphism and G6PD deficiency to be independent predictors of hyperbilirubinemia, this model could explain only a part of the variability. This suggests there may be some more genetic factors that we have not tested for. The fact that history of significant hyperbilirubinemia in the sibling was an independent risk factor would support this. Gestational age is an important known modulator of the risk of hyperbilirubinemia but did not turn out to be an independent predictor in our study. This was because of the case-control study design and inclusion of babies of higher gestations only. Similar observations have been made in other case-control studies (19).

In conclusion, $(\mathrm{TA})_{n}$ promoter polymorphism of the UGTIAl gene was significantly associated with hyperbilirubinemia in North Indian neonates of $\geq 35$-wk gestation, whereas Gly71Arg mutation was neither found in neonates with hyperbilirubinemia nor in controls. A novel polymorphism (Ala72Pro) at nucleotide position $214(214 \mathrm{G} \rightarrow \mathrm{C})$ of exon 1 of UGTIAl gene was found; the significance of which needs to be elucidated. Presence of variant $(\mathrm{TA})_{n}$ promoter, G6PD deficiency, and history of jaundice in sibling requiring phototherapy were independent risk factors of bilirubin levels $\geq 18 \mathrm{mg} / \mathrm{dL}$.

\section{REFERENCES}

1. Setia S, Villaveces A, Dhillon P, Mueller BA 2002 Neonatal jaundice in Asian, white, and mixed-race infants. Arch Pediatr Adolesc Med 156:276-279

2. Narang A, Gathwala G, Kumar P 1997 Neonatal jaundice: an analysis of 551 cases. Indian Pediatr 34:429-432

3. Newman TB, Easterling MJ, Goldman ES, Stevenson DK 1990 Laboratory evaluation of jaundice in newborns. Frequency, cost, and yield. Am J Dis Child 144:364368

4. Kaplan M, Hammerman C 2005 Bilirubin and the genome: the hereditary basis of unconjugated neonatal hyperbilirubinemia. Curr Pharmacogenomics 3:21-42

5. Watchko JF 2004 Genetics and the risk of neonatal hyperbilirubinemia. Pediatr Res $56: 677-678$

6. Monaghan G, Ryan M, Seddon R, Hume R, Burchell B 1996 Genetic variation in bilirubin UDP-glucuronosyltransferase gene promoter and Gilbert's syndrome. Lancet 347:578-581

7. Maruo Y, Nishizawa K, Sato H, Doida Y, Shimada M 1999 Association of neonatal hyperbilinubinemia with bilirubin UDP-glucuronosyltransferase polymorphisms. Pediatrics 103:1224-1227

8. Volpe JJ 2001 Acute bilirubin encephalopathy. In: Volpe JJ (ed) Neurology of the Newborn. W. B. Saunders, Philadelphia, pp 2234

9. Kornberg A, Horecker BL 1955 Glucose-6-phosphate dehydrogenase. In: Colowick SP, Kaplan NO (eds) Methods in Enzymology. Academic Press, New York, pp 323-326
10. Daly AK, Steen VM, Fairbrother KS, Idle JR 1996 CYP2D6 Multiallelism. Methods Enzymol 272:199-210

11. Kaplan M, Renbaum P, Levy-Lahad E, Hammerman C, Lahad A, Beutler E 1997 Gilbert Syndrome and glucose-6-phosphate dehydrogenase deficiency: a dosedependent genetic interaction crucial to neonatal hyperbilirubinemia. Proc Natl Acad Sci USA 94:12128-12132

12. Kumar S, Thapa BR, Kaur G, Prasad R 2006 Familial gene analysis for Wilson disease from north-west Indian patients. Ann Hum Biol 33:177-186

13. Huang MJ, Kua KE, Teng HC, Tang KS, Weng HW, Huang CS 2004 Risk factors for severe hyperbilirubinemia in neonates. Pediatr Res 56:682-689

14. Jendrassik L, Grof P 1938 [Simplified photometric methods for the determination of the bilirubins]. Biochem Z 297:81-89

15. American Academy of Pediatrics Subcommittee on Hyperbilirubinemia 2004 Management of hyperbilirubinemia in the newborn infant 35 or more weeks of gestation. Pediatrics 114:297-316

16. Balram C, Sabapathy K, Fei G, Khoo KS, Lee EJ 2002 Genetic polymorphisms of UDP-glucuronosyltransferase in Asians: UGT1A1*28 is a common allele in Indians. Pharmacogenetics 12:81-83

17. Farheen S, Sengupta S, Santra A, Pal S, Dhali GK, Chakravorty M, Majumder PP, Chowdhury A 2006 Gilbert's syndrome: High frequency of the (TA)7TAA allele in India and its interaction with a novel CAT insertion in promoter of the gene for bilirubin UDP-glucuronosyltransferase 1 gene. World J Gastroenterol 12:2269-2275

18. Premawardhena A, Fisher CA, Liu YT, Verma IC, de Silva S, Arambepola M, Clegg JB, Weatherall DJ 2003 The global distribution of length polymorphisms of the promoters of the glucuronosyltransferase 1 gene (UGT1A1): Hematologic and evolutionary implications. Blood Cells Mol Dis 31:98-101

19. Huang CS, Chang PF, Huang MJ, Chen ES, Hung KL, Tsou KI 2002 Relationship between bilirubin UDP-glucuronosyltransferase 1A1 gene and neonatal hyperbilirubinemia. Pediatr Res 52:601-605

20. Yamamoto A, Nishio H, Waku S, Yokoyama N, Yonetani M, Uetani Y, Nakamura H 2002 Gly71Arg mutation of the bilirubin UDP-glucuronosyltransferase 1A1 gene is associated with neonatal hyperbilirubinemia in Japanese population. Kobe J Med Sci 48:73-77

21. Yusoff S, Rostenberghe HV, Yusoff NM, Talib NA, Ramli N, Ismail ZA, Ismail WP, Matsuo M, Nishio H 2006 Frequencies of A(TA)7TAA, G71R, and G493R mutations of the UGT1A1 gene in the Malaysian population. Biol Neonate 89:171-176

22. Laforgia N, Faienza MF, Rinaldi A, D'Amato G, Rinaldi G, Iolascon A 2002 Neonatal hyperbilirubinemia and Gilbert's syndrome. J Perinat Med 30:166-169

23. Babaoglu MO, Yigit S, Aynacioglu AS, Kerb R, Yurdakok M, Bozkurt A 2006 Neonatal jaundice and bilirubin UDP-glucuronosyl transferase 1A1 gene polymorphism in Turkish patients. Basic Clin Pharmacol Toxicol 98:377-380

24. Muslu N, Turhan AB, Eskandari G, Atici A, Ozturk OG, Kul S, Atik U 2007 The frequency of UDP-glucuronosyltransferase $1 \mathrm{~A} 1$ promotor region (TA)7 polymorphism in newborns and its relation with jaundice. J Trop Pediatr 53:64-68

25. Beutler E, Gelbart T, Demina A 1998 Racial variability in the UDP glucuronosyltransferase 1 (UGT1A1) promoter: a balanced polymorphism for regulation of bilirubin metabolism? Proc Natl Acad Sci USA 95:8170-8174

26. Coelho H, Costa E, Vieira E, Branca R, dos Santos R, Sarbot J 2004 A new case of (TA) 8 allele in the UGT1A1 gene promoter in a Caucasian girl with Gilbert syndrome. Pediatr Hematol Oncol 21:371-374

27. Ostanek B, Furlan D, Mavec T, Lukac-Bajalo J 2007 UGT1A1 (TA)n promoter polymorphism-a new case of a (TA) 8 allele in Caucasians. Blood Cells Mol Dis 38:78-82

28. Bancroft JD, Kreamer B, Gourley GR 1998 Gilbert ssyndrome accelerates the development of neonatal jaundice. J Pediatr 132:656-660

29. Roy-Chowdhury N, Deocharan B, Bejjanki HR, Roy-Chowdhury J, Koliopoulos C, Petmezaki S, Valaes T 2002 Presence of the genetic marker for Gilbert syndrome is associated with increased level and duration of neonatal jaundice. Acta Paediatr 91:100-101

30. Galanello R, Cipollina MD, Carboni G, Perseu L, Barella S, Corrias A, Cao A 1999 Hyperbilirubinemia, glucose-6-phosphate-dehydrogenase deficiency and Gilbert's syndrome. Eur J Pediatr 158:914-916

31. Iolascon A, Faienza MF, Perrotta S, Meloni GF, Ruggiu G, del Giudice EM 1999 Gilbert's syndrome and jaundice in glucose-6-phosphate dehydrogenase deficient neonates. Haematologica 84:99-102

32. Kaplan M, Hammerman C, Beutler E 2001 Hyperbilirubinemia, glucose-6phosphate dehydrogenase deficiency and Gilbert syndrome. Eur J Pediatr 160:195

33. Ritter JK, Crawford JM, Owens IS 1991 Cloning of two human liver bilirubin UDP-glucuronosyltransferase cDNAs with expression in COS-1 cells. J Biol Chem 266:1043-1047

34. SNP structure, function, disease. Available at: http://www.snps3d.org/. Accessed September 1, 2008 